\title{
ИССЛЕДОВАНИЕ ФИТОСТИМУЛИРУЮЩИХ СВОЙСТВ РАСТИТЕЛЬНЫХ ЭКСТРАКТОВ
}

\author{
Гладкая А.А., Настас Т.Н. \\ Институт генетики, физиологии и защчиты растений, Кишинев, Республика Молдова \\ E-mail: asm_igfpp@yahoo.com \\ https://doi.org/10.53040/9789975347204.10
}

\begin{abstract}
We have investigated the phytostimulating properties of Rheum officinale Baill. (Polygonaceae) root and leaves water-ethanol extracts and Azadirachta indica A. Juss. (Meleaceae) seed oil extract, which contain a wide range of bioactive substances. Experiments to determine the effect of treatment with extracts of Cucumis sativus seedlings were carried out in laboratory conditions. The composition V6 $(1 \% \mathrm{R}+0,5 \% \mathrm{~L})$ showed the maximum phytostimulating effect, which increased the plant height by $34,5 \%$, and the number of flowers by $89,6 \%$.
\end{abstract}

Key words: Rheum officinale, Azadirachta indica, Cucumis sativus, extracts, phytostimulating properties.

\section{Введение}

В процессе исследований были изучены фитостимулирующие свойства водноэтанольных экстрактов растения Rheum officinale Baill. (Polygonaceae), (листья и корни), 
которые содержат большой спектр биоактивных веществ. Биохимический состав подземной части Rheum officinale составляют антрахиноны (эмодин, ресвератрол), а листьев - флавонол кверцетин (до 5-6\%), оксалаты и органические кислоты (до 3\%) [1]. Кверцетин (низкомолекулярный антиоксидант, субстрат пероксидазы, антифидант, бактерицид) и эмодин (антифидант, бактерицид, фунгицид) в определенных концентрациях могут проявлять и фитостимулирующий эффект. В регуляции роста растения, важную роль играет негормональный регулятор роста - кверцетин, который входит в состав J3 - ингибиторного комплекса [2]. Эмодин, находящийся в незрелых плодах в больших концентрациях, препятствует прорастанию семян. После созревания плодов, концентрация эмодина в них значительно снижается и появляется противоположный эффект эмодина - стимуляция прорастания семян [3]. Однако механизм этих взаимодействий недостаточно изучен. Известно, также, что проведение опрыскивания и полива растений водным раствором щавелевой кислоты и/или ее кальциевых и/или магниевых солей в течение всего периода вегетации, вызывает модификацию развития растения в нескольких направлениях, одновременно: усиление устойчивости к неблагоприятным факторам среды, замедления процесса старения растений, подавления в почве и на растении развития вредных и нежелательных организмов, ликвидации отпада цветков и завязей овощных растений [4-6]. Рассмотрев свойства вторичных метаболитов ревеня, мы увидели перспективу в использовании побочных продуктов его промышленного использования (листья и корни), в качестве источника соединений, сочетающие в себе несколько типов биологической активности.

В исследованиях был, также, использован масляный экстракт Azadirachta indica A. Juss. (Meleaceae) (семена). В Индии традиционная система земледелия использует экстракты нима для борьбы с вредителями и для снабжения растений питательными веществами [7]. Химический состав масла семян нима богат терпеноидами, лимоноидами и летучими соединениями серы [8]. До настоящего времени было выделено более 300 соединений из различных частей A. indica [9]. Масло семян нима является основным источником жирных кислот и состоит в основном из олеиновой кислоты (50-60\%), пальмитиновой кислоты (13-15\%), стеариновой кислоты (14-19\%), линолевой кислоты (8-16\%) и арахидиновой кислоты (1-3\%) [10]. Ним зарекомендовал себя в качестве удобрения, при этом органические и неорганические соединения, присутствующие в растительном материале, действуют в качестве биоудобрения, обеспечивая макроэлементы, необходимые для роста растений [11].

Цель данной работы состояла в определение фитостимулирующего действия на рассаду огурцов биоактивных веществ экстрактов Rheum officinale (листьев и корней) и Azadirachta indica (семена).

\section{Материалы и методы}

Опыты по изучению влияния обработки экстрактами рассады огурца (Cucumis sativus) сорта «Родничок» были проведены в лабораторных условиях. Известно, что растения могут поглощать элементы не только корневой системой, но и листовой поверхностью. Поглощающая сила листьев составляет от 2 до 5 атмосфер. Поэтому, при обработке растений раствором биоактивных веществ, листья быстро впитывают их, увеличивая свою синтетическую деятельность, что позволяет значительно уменьшить стрессы растений от природных аномалий погоды (высокая температура, заморозки), приспосабливает их к окружающей среде, активизирует корневое питание, замедляет старение растения и создает условия для получения высокого и качественного урожая. 
Листья рассады огурца (C. sativus), выращенной в пластиковых емкостях с почвенной смесью, были обработаны рандомизированно, в 4-х кратной повторности, следующими составами: V1 - $(0,5 \% \mathrm{R}), \mathrm{V} 2$ - $(1 \% \mathrm{R}), \mathrm{V} 3$ - $(0,1 \% \mathrm{~L}), \mathrm{V} 4$ - $(0,5 \% \mathrm{~L}), \mathrm{V} 5$ $(0,5 \% \mathrm{R}+0,1 \% \mathrm{~L}), \mathrm{V} 6-(1 \% \mathrm{R}+0,5 \% \mathrm{~L}), \mathrm{V} 7-(0,5 \% \mathrm{~N}), \mathrm{V} 8-(0,5 \% \mathrm{R}+0,1 \% \mathrm{~L}+0,5 \% \mathrm{~N}), \mathrm{V} 9-$ $(1 \% \mathrm{R}+0,5 \% \mathrm{~L}+1 \% \mathrm{~N})$. Контрольные растения не обрабатывали. Через 4 недели провели учет высоты растений, количества цветов и листьев (Рис. 1).

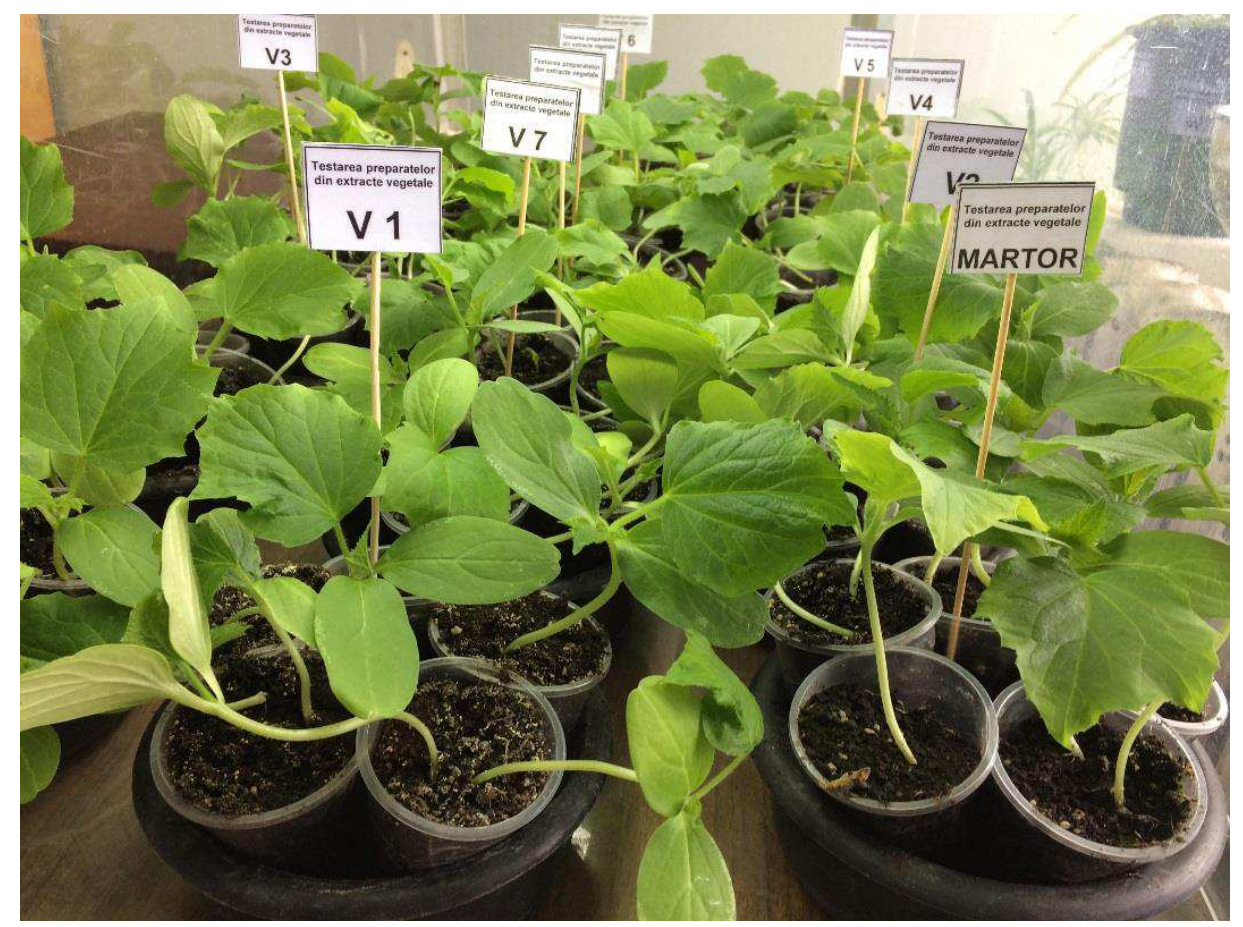

Рисунок 1. Опыты по изучению влияния обработки экстрактами Rheum officinale и Azadirachta indica рассады огурца в лабораторных условиях.

Для построения графических материалов использовали пакет программ Microsoft Office Excel. Математическая обработка и оценка достоверности полученных научных данных проведена с использованием платформы ABC Pascal.

\section{Результаты и обсуждение}

Полученные результаты еженедельных обработок рассады огурца указывали на то, что экстракты, и их композиции, оказали стимулирующее действие на рост растений и количество цветов, в то время как количество листьев оставалось в пределах погрешности с контрольным вариантом. Так, было установлено, что экстракт из листьев ревеня ( $\mathrm{V} 4$ - 0,5\%L) оказал стимулирующее действие на рост растений (на $34,9 \%$ больше контрольных значений), не повлияв на количество листьев и цветов. Одновременно было доказано, что экстракт из корня ревеня (V1 - 0,5\%R), в меньшей степени повлиял на увеличение роста растений (на 23,7\%), но существенно повлиял на увеличения количество цветков (на $85,5 \%$ в сравнение с контрольным вариантом). Максимальный фито стимулирующий эффект проявила композиция (V6 - 1\% R+0,5\% L), которая существенно усилил рост растений на $34,5 \%$ и увеличила количество цветков на $89,6 \%$ в сравнение с контрольным вариантом. 
В ходе исследований нами было установлено, что и масляный экстракт из семян Azadirachta indica также проявил определенный стимулирующий эффект на рост растений в пределах 19\% и увеличение количество цветков на $76 \%$ в сравнение с контрольным вариантом (Таблица 1).

Таблица 1. Влияние обработки растительными экстрактами Rheum officinale и Azadirachta indica, и их композициями на физиологические показатели рассады огурца

\begin{tabular}{|c|c|c|c|}
\hline Вариант & $\begin{array}{c}\text { Высота } \\
\text { растения (см) }\end{array}$ & $\begin{array}{c}\text { Кол-во } \\
\text { листьев/растение }\end{array}$ & $\begin{array}{c}\text { Кол-во } \\
\text { цветов/растение }\end{array}$ \\
\hline Контроль & 29,3 & 7,0 & 1,2 \\
\hline $\mathrm{V} 1(0,5 \% \mathrm{R})$ & 39,2 & 7,4 & 8,3 \\
\hline $\mathrm{V} 2(1 \% \mathrm{R})$ & 35,5 & 5,4 & 5,0 \\
\hline V3 $(0,1 \% \mathrm{~L})$ & 36,6 & 7,7 & 3,7 \\
\hline $\mathrm{V} 4(0,5 \% \mathrm{~L})$ & 45,0 & 8,0 & 3,1 \\
\hline V5 $(0,5 \% \mathrm{R}+0,1 \% \mathrm{~L})$ & 42,3 & 7,0 & 8,3 \\
\hline V6 (1\% R+0,5\%L) & 44,7 & 6,4 & 11,5 \\
\hline $\mathrm{V} 7(0,5 \% \mathrm{~N})$ & 36,2 & 7,1 & 5,0 \\
\hline V8 $(0,5 \% \mathrm{R}+0,1 \% \mathrm{~L}+0,5 \% \mathrm{~N})$ & 31,8 & 5,2 & 7,6 \\
\hline V9 (1\% R+0,5\%L+1\%N ) & 36,3 & 6,5 & 5,9 \\
\hline $\mathrm{HCP}_{0,05}$ & 6,6 & 1,5 & 3,2 \\
\hline
\end{tabular}

Условные обозначения: экстракты $\mathrm{R}$ - корня Rheum officinale; L - листьев Rheum officinale; $\mathrm{N}$ - семян Azadirachta indica.

\section{Выводы}

Биоактивные вещества экстрактов Rheum officinale (листьев и корней) и Azadirachta indica (семена) оказали на растения рассады огурца активное фитостимулирующее действие. Экстракты представляют достойную альтернативу для синтетических регуляторов роста растений благодаря экологичности, простоте использования, эффективности и безопасности.

\section{Библиография}

1. Костикова В.А., Высочина Г.И., Петрук А.А. Особенности накопления флавоноидов в органах надземной части Rheum compactum. В: Химия растительного сырья. 2015, №4, с. 147-150. ISSN 1029-5143.

2. Рогожин В.В., Верхотуров В.В. Влияние антиоксидантов (дигоксина, кверцетина и аскорбиновой кислоты) на каталитические свойства пероксидазы хрена. В: Биохимия, 1998, т. 63, № 6, с. 63-68. ISSN 1608-3040.

3. Cipollini M.L., Levey D.J. Secondary metabolites of fleshy vertebrate dispersed fruits: adaptive hypotheses and implications for seed dispersal. In: American Naturalist. 1997, vol. 150, pp. 346-372. ISSN 0003-0147.

4. Правдивцев В.А. Модификатор (стимулятор) для обработки растений и способ его использования. Патент РФ № 2201079, дата публикации 27.03.2003. (просмотрено 03.08.2019)

5. Сорочкин, И.Н. и другие. Регулятор роста растений., Патент РФ № 2355169. дата публикации 20.05.2009. (просмотрено 03.08.2019)

6. Верещагин, Ф.Л. и другие. Способ стимулирования растений. Патент РФ № 2267924. ЗАО СХП «Озерское», дата публикации 20.01.2006. (просмотрено 03.08.2019) 
7. Mossini S., Kemmelmeier C. Aarvore Nim (Azadirachta indica A. Juss): multiplosusos. Acta Farm Bonaer. 2005; 24:139-148.

8. Lokanadhan $\mathrm{S}$, Muthukrishnan $\mathrm{P}$, Jeyaraman $\mathrm{S}$. Neem products and their agricultural applications. Journal of Bio pesticide. 2012; 5:72-76.

9. Benelli G, Bedini S, Cosci F, Toniolo C, Conti B, Nicoletti M. Larvicidal and ovideterrent properties of neem oil and fractions against the filariasis vector Aedes albopictus (Diptera: Culicidae): A bioactivity survey across production sites. Parasitology Research. 2015; 114(1):227-236.

10. Narsing Rao G, Prabhakara Rao Pg, Satyanarayana A. Chemical, fatty acid, volatile oil composition and antioxidant activity of shade dried neem (Azadirachta indica L.) flower powder. International Food Research Journal. 2014; 21(2):807-813.

11. Lokanadhan S, Muthukrishnan P, Jeyaraman S. Neem products and their agricultural applications. Journal of Bio pesticide. 2012; 5:72-76. 